\title{
Characterization and inactivation of the membrane- bound polyol dehydrogenase in Gluconobacter oxydans DSM 7145 reveals a role in meso- erythritol oxidation
}

Correspondence

Armin Ehrenreich

aehrenr@mikro.biologie.

tu-muenchen.de
Received 23 December 2009

Revised 4 March 2010

Accepted 5 March 2010

\author{
Jörn Voss, ${ }^{1}$ Armin Ehrenreich ${ }^{2}$ and Wolfgang Liebl ${ }^{2}$ \\ ${ }^{1}$ Institute of Microbiology and Genetics, Georg-August Universität, Grisebachstr. 8, D-37077 \\ Göttingen, Germany \\ ${ }^{2}$ Department of Microbiology, Technische Universität München, Emil-Ramann-Str. 4, D-85354 \\ Freising-Weihenstephan, Germany
}

\section{INTRODUCTION}

Gluconobacter oxydans is one of the most important organisms in industrial biotechnology because of its ability to incompletely oxidize various sugars, sugar alcohols and sugar acids (De Muynck et al., 2007). The oxidation reactions are catalysed by membrane-bound dehydrogenases linked to the respiratory chain (Matsushita et al., 1994). As the active sites of these dehydrogenases face the periplasm, substrates need not be transported into the cytoplasm and the corresponding oxidation products accumulate in the culture medium. Moreover, most substrates are oxidized regio- and stereoselectively, yielding enantiomerically pure products at high yields, thus enabling efficient whole-cell biocatalytic production processes that are superior to chemical substrate conversion

Abbreviations: DCIP, 2,6-dichlorophenol indophenol; Gm, gentamicin; $\mathrm{Km}$, kanamycin; PMS, phenazine methosulfate; PQQ, pyrroloquinoline quinone; RLM RACE, RNA ligase-mediated rapid amplification of cDNA ends.

A supplementary figure, showing an alignment of the amino acid sequences of the SIdB and SIdA proteins of G. oxydans ATCC $621 \mathrm{H}$ (Gox0855) and G. oxydans DSM 7145, is available with the online version of this paper. due to the absence of complicated and expensive protective chemistry reactions (Schweiger et al., 2007). Examples of the industrial application of Gluconobacter spp. are the production of L-sorbose, an intermediate of vitamin C synthesis (Adachi et al., 2003) and the conversion of 1amino-D-sorbitol to 6-amino-L-sorbose for the synthesis of the antidiabetic drug Miglitol (Schedel, 2000).

All of the biochemically studied membrane-bound dehydrogenases are either quinoproteins, containing pyrroloquinoline quinone (PQQ) as prosthetic group, or flavoproteins, containing a covalently bound FAD molecule (Davidson, 2004; Matsushita et al., 1994). Additionally, some enzymes contain a haem $c$ moiety, such as the quinohaemoprotein alcohol dehydrogenase (Kondo \& Horinouchi, 1997). The reducing equivalents derived from the oxidation reactions are transferred via ubiquinone to a chinol oxidase of the bo $o_{3}$ type (Matsushita et al., 1987), with concomitant build-up of an electrochemical proton gradient across the cytoplasmic membrane. Therefore, the incomplete oxidation reactions provide energy for growth, while the cytoplasmic, NAD $(\mathrm{P})$-dependent dehydrogenases present in Gluconobacter spp. most likely provide precursors for biosynthetic pathways (Matsushita et al., 1994). 
The membrane-bound quinoprotein glycerol dehydrogenase of the Gluconobacter suboxydans strains IFO 3257 and IFO 3255, which contains PQQ as prosthetic group, has been shown to be a versatile enzyme, catalysing the oxidation of the sugar acid D-gluconate and the sugar alcohols glycerol, D-arabitol, D-mannitol and D-sorbitol (Matsushita et al., 2003). It is composed of the large SldA subunit $(79.6 \mathrm{kDa})$, which contains the active site, and the small SldB subunit ( $14 \mathrm{kDa})$, which is essential for activity development and seems to act as a molecular chaperone (Shinjoh et al., 2002). The enzyme catalyses the regio- and stereoselective oxidation of its substrates according to the Bertrand-Hudson rule, which states that polyols with a cis arrangement of two secondary hydroxyl groups in D-configuration to the primary alcohol group (D-erythro configuration) are oxidized to the corresponding ketoses (Kulhanek, 1989). Also among these substrates is the tetritol meso-erythritol, which is oxidized to the corresponding ketose L-erythrulose (Matsushita et al., 2003). L-Erythrulose is commonly used as tanning agent and constitutes a precursor for the production of L-erythrose, a derivative of which, dideoxyerythrose, has shown some anti-HIV activity (Tschamber et al., 1996).

Despite the fact that Gluconobacter oxydans is used for the industrial conversion of meso-erythritol to L-erythrulose, the utilization and oxidation of erythritol by this species has not been studied in detail. In this study we have shown that the membrane-bound glycerol dehydrogenase catalyses meso-erythritol oxidation in G. oxydans DSM 7145 , and that both meso-erythritol and L-erythrulose are utilized by G. oxydans DSM 7145. Additionally, the genetic organization of the genes sldA and sldB was investigated.

\section{METHODS}

Bacterial strains and growth conditions. All strains and plasmids and their relevant characteristics are listed in Table 1. Escherichia coli strains were grown in Luria-Bertani medium (Sambrook et al., 1989) at $37{ }^{\circ} \mathrm{C}$ and 150 r.p.m. G. oxydans DSM 7145 and its derivatives were routinely grown in a complex medium containing $5 \mathrm{~g}$ yeast extract $1^{-1}, 3 \mathrm{~g}$ tryptone $1^{-1}$ and $50 \mathrm{mM}$ D-mannitol ( $\mathrm{pH} \mathrm{6.0).} \mathrm{When}$ appropriate, D-mannitol was replaced by $50 \mathrm{mM}$ D-glucose. Growth was recorded by measuring the $\mathrm{OD}_{600}$ in a UV-Vis spectrophotometer (Amersham). Growth tests were performed in complex medium, using cultures pre-grown on the respective substrate as inoculum. The following substrates were tested at final concentrations of $50 \mathrm{mM}$ : Dmannitol, D-glucose, glycerol and meso-erythritol. A mixture of Dglucose and D-mannitol was added at a final concentration of $25 \mathrm{mM}$ each. Antibiotics were used at the following concentrations: kanamycin $\left(\mathrm{Km} ; 50 \mu \mathrm{g} \mathrm{ml}^{-1}\right)$, cefoxitin $\left(50 \mu \mathrm{g} \mathrm{ml}^{-1}\right)$ and gentamicin (Gm) $50 \mu \mathrm{g} \mathrm{ml}^{-1}$ (G. oxydans) or $10 \mu \mathrm{g} \mathrm{ml}^{-1}$ (E. coli).

Resting cell experiments. G. oxydans DSM 7145 was grown to stationary phase $\left(\mathrm{OD}_{600} \sim 1.1\right)$ in $300 \mathrm{ml}$ complex medium with $50 \mathrm{mM}$ D-glucose. The cells were harvested by centrifugation at 10000 r.p.m. and subsequently washed twice with $10 \mathrm{mM}$ sodium phosphate buffer ( $\mathrm{pH}$ 6.2). The pellets of $150 \mathrm{ml}$ culture were resuspended in $100 \mathrm{ml} 10 \mathrm{mM}$ sodium phosphate buffer ( $\mathrm{pH}$ 6.2) containing either 50 or $200 \mathrm{mM}$ meso-erythritol, transferred to a 11 flask and incubated at $30{ }^{\circ} \mathrm{C}, 150$ r.p.m. for $24 \mathrm{~h}$.

DNA manipulations. Routine molecular biology experiments were carried out with commonly used standard procedures. Genomic DNA from G. oxydans DSM 7145 for PCRs and Southern blot analysis was prepared using the MasterPure DNA purification kit (Epicentre). Pfu DNA polymerase (Fermentas) was used for amplification of fragments that were subsequently cloned. Taq DNA polymerase (Fermentas) was employed in test reactions. Primers used in this study are listed in Table 2 and were deduced from the whole genome sequence of G. oxydans ATCC $621 \mathrm{H}$ (Prust et al., 2005). Restriction enzymes (Fermentas), DNA ligase and antarctic phosphatase (New England Biolabs) were all used according to the manufacturers' instructions.

Table 1. Strains used and constructed in this study

Abbreviations: $\mathrm{Ap}^{\mathrm{R}}$, ampicillin resistant; $\mathrm{Gm}^{\mathrm{R}}$, gentamicin resistant; $\mathrm{Km}^{\mathrm{R}}$, kanamycin resistant; Strep ${ }^{\mathrm{R}}$, streptomycin resistant.

\begin{tabular}{|c|c|c|}
\hline Strain or plasmid & Relevant characteristics & Source or reference \\
\hline \multicolumn{3}{|l|}{ E. coli strains } \\
\hline XL-1 blue & rec $\mathrm{A}^{-}$, thi, hsd $\mathrm{R} 1, \sup \mathrm{E} 44, \operatorname{rel} \mathrm{A} 1, \operatorname{lac} \mathrm{F}^{\prime}$, proAB, lacIq, lacZ $\Delta \mathrm{M} 15$, Tn $10[$ Tet] & Bullock et al. (1987) \\
\hline Solopack & lacZ $\Delta \mathrm{M} 15$, end $\mathrm{A}, \operatorname{rec} \mathrm{A}^{-}$, Strep $^{\mathrm{R}}$, cre & Stratagene \\
\hline \multicolumn{3}{|l|}{ G. oxydans strains } \\
\hline DSM 7145 & Type strain & Mason \& Claus (1980) \\
\hline \multicolumn{3}{|l|}{ Plasmids } \\
\hline pSC-A & Cloning vector, $\mathrm{Ap}^{\mathrm{R}}$ & Stratagene \\
\hline pBBR-1 MCS2 & Broad-host-range vector, $\mathrm{Km}^{\mathrm{R}}$ & Kovach et al. (1995) \\
\hline pBBR-1 MSC5 & Broad-host-range vector, $\mathrm{Gm}^{\mathrm{R}}$ & Kovach et al. (1995) \\
\hline pK19mobsacB & Gene replacement vector, $\mathrm{Km}^{\mathrm{R}}$, sacB & Schäfer et al. (1994) \\
\hline pSC-A : sldAB & sldBA genes in $\mathrm{pSC}-\mathrm{A}, \mathrm{Ap}^{\mathrm{R}}$ & This study \\
\hline
\end{tabular}


Table 2. Primers used in this study

\begin{tabular}{|c|c|c|}
\hline Primer & Sequence $\left(5^{\prime} \rightarrow 3^{\prime}\right)$ & Source or reference \\
\hline sldB_for & GACTTACCGTCCGGACTTTCAGTTCTG & This work \\
\hline sldB_rev & CGTGGCACAGGCAACGGTGGCGAGAAG & This work \\
\hline sldA_for & GTCTGATGCGCAGATCCCATCTTCTCG & This work \\
\hline sldA_rev & CGCTTTCTCAGCCCTTGTGATCAGGCAGTG & This work \\
\hline sldA_w1 & GCTTTCGTCTATCACACCGGTAGC & This work \\
\hline sldA_w2 & GTAGAGGCCGTCACCCACCTTGATC & This work \\
\hline sldA_w3 & GATACCGTAAGGCGTGCCGTC & This work \\
\hline sld $A \_$w4 & ACGTAGACGAGGCCCAGCGCATT & This work \\
\hline sld $A \_$w5 & GACAATGCGCTGGGCCTCGTC & This work \\
\hline sld $A \_$w6 & GACCAGCTCGTAACCCGCAAG & This work \\
\hline sldB_v_for & ATGCCGCGGTCAGTTACAACAACAC & This work \\
\hline sldA_v_rev & GCCGGAAGAACCTGAAGGATGACGGGAG & This work \\
\hline sldA_p_for & GCGTCCATGGACGGCACGCCTTA & This work \\
\hline sldB_prom_for & CATTTGAATTTGTTGAAGTGCAACC & This work \\
\hline sldB_prom_rev & ATCTGCGCATTGGTGAAAGCCTCCAGAACTGAAAG & This work \\
\hline sldA_compl_for & GCTTTCACCAATGCGCAGATCCCATCTTCTCGCCA & This work \\
\hline sldA_compl_rev & GCTTTCTCAGCCCTTGTGATCAGG & This work \\
\hline sld $B \_$RC_out & GCTCGAAGGAATTGCCGCTGCCAT & This work \\
\hline Genta_1_for & CCATGGACGCACACCGTGGAAACGGATGA & This work \\
\hline Genta_2_rev & CCATGGACGCCCTGGGGCCGTTGAATC & This work \\
\hline 5' RACE_outer & GCTGATGGCGATGAATGAACACTG & Ambion \\
\hline 5' RACE_inner & CGCGGATCCGAACACTGCGTTTGCTGGCTTTGATG & Ambion \\
\hline
\end{tabular}

Nucleotide sequence analysis. Sequencing was performed using an ABI Prism 3730XL sequencer (Applied Biosystems). The nucleotide sequences were determined on both DNA strands. Sequence data were analysed using the STADEN software package (Bonfield et al., 1995). Homology searches and alignment analysis were performed using BLAST (Altschul et al., 1997) and CLUSTAL W (Larkin et al., 2007), respectively. Potential signal peptides and transmembrane helices were predicted with the SignalP 3.0 software (Bendtsen et al., 2004) and тмнмм software, respectively.

Southern blot analysis. Two micrograms of genomic DNA was digested with $K p n \mathrm{I}$ and electrophoresed on an $0.8 \%$ agarose gel, transferred to a positively charged Hybond XL membrane (Amersham Biosciences), and hybridized with a probe generated by amplification with primers sldA_p_for/sldA_rev (Table 2) and plasmid pJV5 (Table 1) as template. Labelling and detection were carried out using the Biotin DecaLabel DNA Labeling and Biotin Chromogenic Detection kit (both Fermentas) according to the manufacturer's protocols.

Transcription analysis. G. oxydans DSM 7145 total RNA was prepared from $40 \mathrm{ml}$ cells grown to late exponential phase on complex medium with either D-glucose or D-glucose/D-mannitol using the RNeasy Midi kit (Qiagen) according to the manufacturer's protocol with the following modifications: cells were resuspended in $200 \mu \mathrm{l}$ TE buffer (10 mM Tris, $1 \mathrm{mM}$ EDTA, pH 7.5) and opened by mechanical disruption, and the frozen powder was then instantly resuspended in $4 \mathrm{ml}$ of the RLT (RNeasy lysis) buffer provided. The prepared RNA was then treated with DNase (Roche) followed by phenol/chloroform extraction and subsequent precipitation with $0.3 \mathrm{M}$ sodium acetate and $70 \%(\mathrm{v} / \mathrm{v})$ ethanol. RNA integrity was verified using a Bioanalyser 2100 (Agilent).

RT-PCR. RT-PCRs were performed using the OneStep RT-PCR kit (Qiagen) according to the instructions of the manufacturer and using $800 \mathrm{ng}$ total RNA as template. To verify co-transcription of the sldBA genes, primers sldB_for and sldA_w2 (Table 2) were used. Primer sldB_for binds at the $5^{\prime}$ end of the sldB gene, while primer sldA_w2 binds in the opposite direction starting at basepair 504 of the sldA gene. A polycistronic mRNA was expected to yield a product of 924 bp.

Mapping of the s/dBA transcription start site. RNA ligasemediated rapid amplification of cDNA ends (RLM RACE) was used to determine the transcription start site of the sldBA genes, using the protocol of the manufacturer (FirstChoice RLM-RACE kit, Ambion). Two independent replicates were carried out, including a control without tobacco acid pyrophosphatase treatment. The generated cDNA was subsequently used in a nested PCR with Taq DNA polymerase (Fermentas) and the primers listed in Table 2. After column purification (Qiagen), products were cloned using a TOPO TA cloning kit (Invitrogen). A total of four colonies were analysed, and the insert was sequenced in both directions.

Construction of a G. oxydans DSM 7145 s/dA mutant. To construct a $G$. oxydans DSM 7145 sldA mutant by allelic replacement, the $s l d B A$ genes were amplified with forward primer sldB_for and reverse primer sldA_rev (Table 2) from genomic DNA of G. oxydans DSM 7145 and cloned into plasmid pSC-A (Stratagene). The central $1.5 \mathrm{~kb} \mathrm{NcoI}$ fragment from the sldBA insert in pSC-A : sldAB was then replaced with a $1 \mathrm{~kb}$ Gm-resistance cassette which had previously been amplified from plasmid pBBR-1 MCS5 (Kovach et al., 1995) using primers Genta_1_for and Genta_2_rev (Table 2). The correct insertion of the Gm-resistance cassette in the same transcriptional direction as the $s l d B$ gene was confirmed by restriction endonuclease digestion. The insert was finally cloned between the HindIII and EcoRI sites of plasmid pK19mobsacB (Schäfer et al., 1994), resulting in plasmid pJV5. Plasmid pJV5 was transformed into E. coli S17-1 (Simon et al., 1983) and mobilized into G. oxydans DSM 7145. Singlecrossover mutants were selected by plating on complex medium with $\mathrm{Km}$. Double-crossover mutants were identified based on their $\mathrm{Km}^{\mathrm{s}}$ / $\mathrm{Gm}^{\mathrm{r}}$ phenotype. 
Construction of a complementation vector. To complement the sldA mutant, a $143 \mathrm{bp}$ fragment containing the putative promoter region of the $s l d B A$ genes was amplified using primers sldB_prom_for and sldB_prom_rev (Table 2) and genomic DNA as template. Similarly, the sldA structural gene $(2.2 \mathrm{~kb})$ was amplified using primers sldA_compl_for and sldA_compl_rev (Table 2). Both fragments were fused in a long flanking homology PCR (Wach, 1996), and the obtained $2.3 \mathrm{~kb}$ fragment was subcloned into vector pSC-A (Stratagene). The insert was excised from pSC-A : sldAB_prom by EcoRI digestion and finally cloned between the EcoRI sites of pBBR-1 MCS2 (Kovach et al., 1995), resulting in plasmid pJV8. The construct was transferred into G. oxydans DSM 7145 by biparental mating using E. coli S17-1.

Preparation of membrane fractions. G. oxydans DSM 7145 and G. oxydans DSM 7145 sldA:: Gm were grown on $300 \mathrm{ml}$ complex medium with D-glucose or D-glucose/D-mannitol to late exponential phase. Cultures were harvested by centrifugation (9000 r.p.m., $15 \mathrm{~min}$ ), washed twice with $10 \mathrm{mM}$ Tris/HCl buffer $(\mathrm{pH} 7.2)$ and resuspended in $10 \mathrm{ml}$ of the same buffer per gram wet weight. Cells were lysed by twofold passage through a French press, and after centrifugation (11000 r.p.m., $20 \mathrm{~min}$ ) to remove intact cells, the supernatant (crude extract) was centrifuged at $100000 \mathrm{~g}$ for $2 \mathrm{~h}$. The resulting pellet was suspended in $10 \mathrm{mM}$ Tris/ $\mathrm{HCl}$ buffer $(\mathrm{pH} 7.2)$, centrifuged again $(100000 \mathrm{~g}, 60 \mathrm{~min})$, resuspended in the same buffer and designated membrane fraction.

Protein determination. Protein concentrations were determined with a Bradford assay with the modification for determining protein concentrations of membrane fractions described by Pestov \& Rydström (2007). BSA was used as standard.

Dehydrogenase assay. Dehydrogenase activities were assayed spectrophotometrically by following the reduction of 2,6-dichlorophenol indophenol (DCIP) at $578 \mathrm{~nm}$ using phenazine methosulfate (PMS) as a redox mediator. The reaction mixture contained enzyme solution, MacIllvaine buffer ( $\mathrm{pH} 5.0$ ), $25 \mathrm{mM}$ substrate, $0.67 \mathrm{mM}$ PMS and $0.1 \mathrm{mM}$ DCIP. Reactions were started by addition of substrate and followed in a Varian Model 100 spectrophotometer. One unit of enzyme activity was defined as the amount of enzyme oxidizing $1 \mu \mathrm{mol}$ substrate $\min ^{-1}$. The specific activity was calculated using a millimolar extinction coefficient for DCIP of $5.016 \mathrm{M}^{-1} \mathrm{~cm}^{-1}$ at pH 5.0 and $578 \mathrm{~nm}$.

Substrate/product analyses. Samples from cultures for the determination of meso-erythritol and L-erythrulose were obtained by centrifugation at 13000 r.p.m. for $10 \mathrm{~min}$ and subsequent freezing at $-20{ }^{\circ} \mathrm{C}$. meso-Erythritol and L-erythrulose were quantified by HPLC using a CarboPac MA1 or PAl column (Dionex). Sample volumes of $100 \mu \mathrm{l}$ were injected and the temperature was kept constant at $25{ }^{\circ} \mathrm{C}$. Each run was carried out isocratically using $480 \mathrm{mM}$ (CarboPac MA1) or $250 \mathrm{mM}$ (CarboPac PA1) $\mathrm{NaOH}$ elution buffer. meso-Erythitol and L-erythrulose peaks were detected electrochemically after approximately 1.8 and $2.5 \mathrm{~min}$, respectively (CarboPac MA1 10.8 and $26.8 \mathrm{~min}$, respectively). Acetate was assayed enzymically as described by Bergmeier (1974) with an acetate detection kit (R-Biopharm) according to the instructions of the manufacturer.

\section{RESULTS}

\section{Growth of G. oxydans DSM 7145 on meso- erythritol-containing medium}

As shown in Fig. 1, G. oxydans DSM 7145 grew at $30{ }^{\circ} \mathrm{C}$ on complex medium supplemented with $50 \mathrm{mM}$ meso- erythritol at a growth rate of $0.51 \mathrm{~h}^{-1}$ and to a final optical density of 1.82. HPLC analysis of culture supernatants revealed that meso-erythritol was nearly quantitatively oxidized to L-erythrulose within the first $8 \mathrm{~h}$ of the experiment, which coincided with an increase in optical density from 0.05 to 0.8 . However, the extracellular Lerythrulose concentration decreased by approximately $60 \%$ in a second growth phase from $t_{8}$ to $t_{24}$, where a further increase in optical density was observed (0.8-1.82). To identify reaction products secreted in the second growth phase, culture supernatants were analysed by HPLC and GC-MS analysis. These analyses identified acetic acid as the main reaction product (data not shown), which was also confirmed enzymically. Acetic acid starts to accumulate as the supplied meso-erythritol is completely oxidized. While the extracellular L-erythrulose concentra-
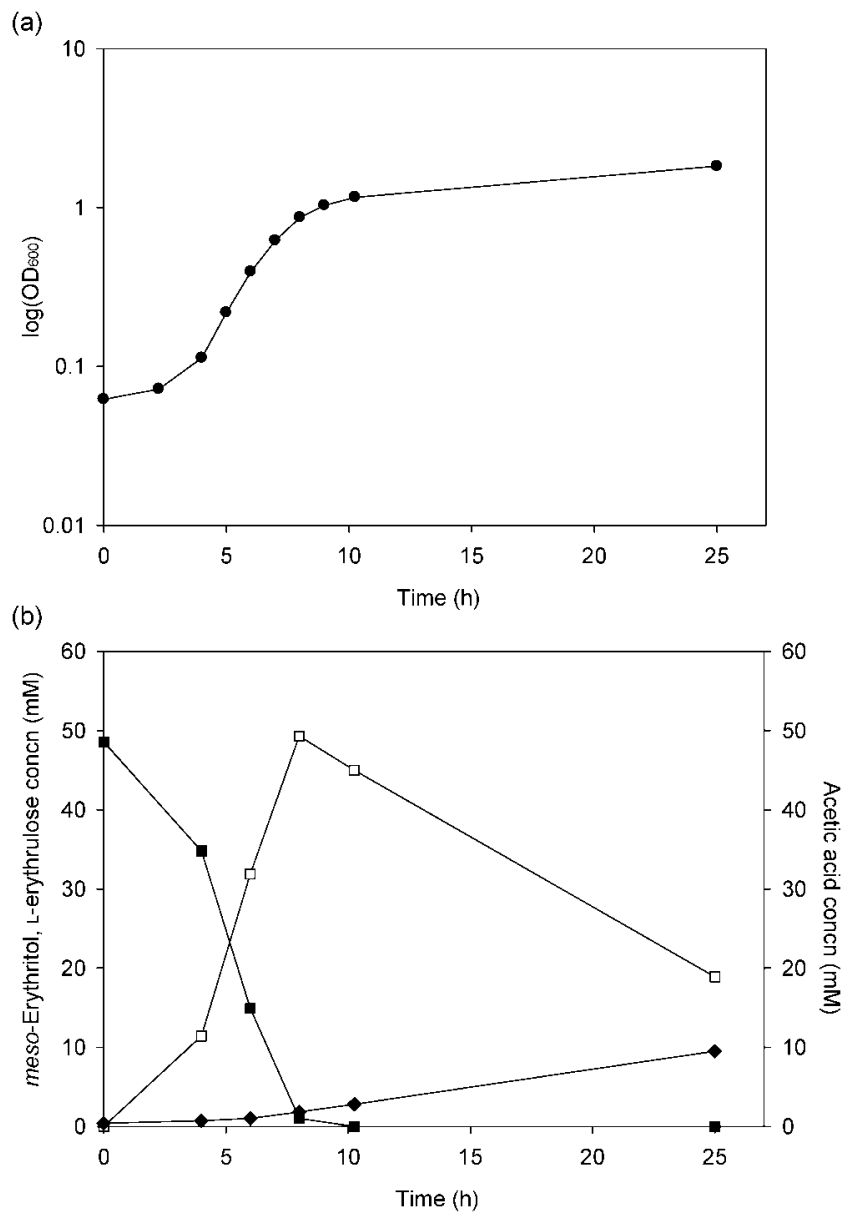

Fig. 1. Growth and substrate/product analysis of G. oxydans DSM 7145 on complex medium supplemented with $50 \mathrm{mM}$ mesoerythritol. A representative experiment is shown. (a) Growth of the culture was followed spectrophotometrically after starting the culture at $\mathrm{OD}_{600}$ 0.07. (b) Substrate consumption and product formation during growth were quantified as described in Methods. Symbols: $\boldsymbol{\square}$, meso-erythritol concentration (mM); $\square$, L-erythrulose concentration (mM); $\diamond$, acetic acid concentration (mM). 
tion decreased by $30 \mathrm{mM}$, only $10 \mathrm{mM}$ acetic acid was detectable in the supernatant (Fig. 1b).

Resting cells of G. oxydans DSM 7145 rapidly converted $50 \mathrm{mM}$ meso-erythritol to L-erythrulose within $6 \mathrm{~h}$ with a yield of $93 \%$ (Fig. 2). Interestingly, neither a decrease in extracellular L-erythrulose concentration nor an accumulation of acetic acid was observed in the resting cell experiments. Taken together, these results indicate that Lerythrulose consumption and acetic acid production can be attributed to growth of G. oxydans DSM 7145 on Lerythrulose.

\section{Sequence analysis of s/dBA from G. oxydans DSM 7145}

As meso-erythritol oxidation was solely localized in membrane fractions of G. oxydans DSM 7145 (data not shown) it was hypothesized that an enzyme similar to the membrane-bound glycerol dehydrogenase of G. suboxydans (Matsushita et al., 2003) catalyses oxidation of mesoerythritol in G. oxydans DSM 7145. Therefore, potential homologues of the sldBA genes, encoding the glycerol dehydrogenase, were amplified. Not only the product sizes obtained, $\sim 380 \mathrm{bp}$ for $s l d B, \sim 2200 \mathrm{bp}$ for $s l d A$, but also the sequences of the sldBA genes of G. oxydans DSM 1745 and ATCC $621 \mathrm{H}$ were highly similar.

Based on the deduced amino acid sequences a complete identity of the SldB and a $99 \%$ identity of the SldA proteins of G. oxydans DSM 7145 and G. oxydans ATCC $621 \mathrm{H}$ was observed (Supplementary Fig. S1). The SldB protein contains three putative transmembrane helices, while no transmembrane helices were predicted for the SldA protein. Furthermore, a 24 amino acid signal sequence was identified at the $\mathrm{N}$ terminus of the SldA protein.

Based on the structure of the Methylobacterium extorquens methanol dehydrogenase (Ghosh et al., 1995) two highly conserved residues could be identified in the SldA amino acid sequence. Among these residues is Trp-340, which lies at the same position as Trp-243 of the methanol dehydrogenase, where this residue together with two sulfur atoms of a disulfide ring structure plays a key role in positioning the PQQ molecule. Interestingly, the Trp residue alone, and neither the two cysteine residues nor a histidine residue, which replaces the cysteine residues in the E. coli quinoprotein glucose dehydrogenase (Cozier \& Anthony, 1995), was detectable in the SldA amino acid sequence. However, the SldA protein retains an Asp residue (Asp-404, Supplementary Fig. S1), conserved in all PQQdependent dehydrogenases, which corresponds to Asp-303 of the $M$. extorquens methanol dehydrogenase and is thought to be the catalytic base that initiates the reaction by abstraction of a proton from the substrate (Ghosh $e t$ al., 1995).

\section{Genetic organization of $s / d A$ and $s / d B$ in $G$. oxydans DSM 7145}

Sequencing of the sld genes revealed that the stop codon of the sldB gene (TGA) overlaps with the start codon (ATG) of the sldA gene, suggesting that the sldBA genes are organized in an operon. To analyse whether the sldBA genes are co-transcribed, an RT-PCR with primers spanning the entire sldB gene and the $5^{\prime}$ portion of the sldA gene was performed. As shown in Fig. 3, the expected $\sim 920 \mathrm{bp}$ fragment, originating from a polycistronic mRNA, was obtained. Additionally, the transcription start of the sldBA genes was mapped by $5^{\prime}$ RLM RACE at the thymidine nucleotide $24 \mathrm{bp}$ upstream of the $s l d B$ start codon, which further supports the notion that in $G$. oxydans DSM 7145 the sldBA genes are co-transcribed from a common promoter upstream of $s l d B$ (data not shown).

\section{Disruption of the s/dA gene in G. oxydans DSM 7145}

To test the hypothesis that meso-erythritol oxidation in G. oxydans DSM 7145 is catalysed by the glycerol dehydrogenase, a mutant was constructed by chromosomal
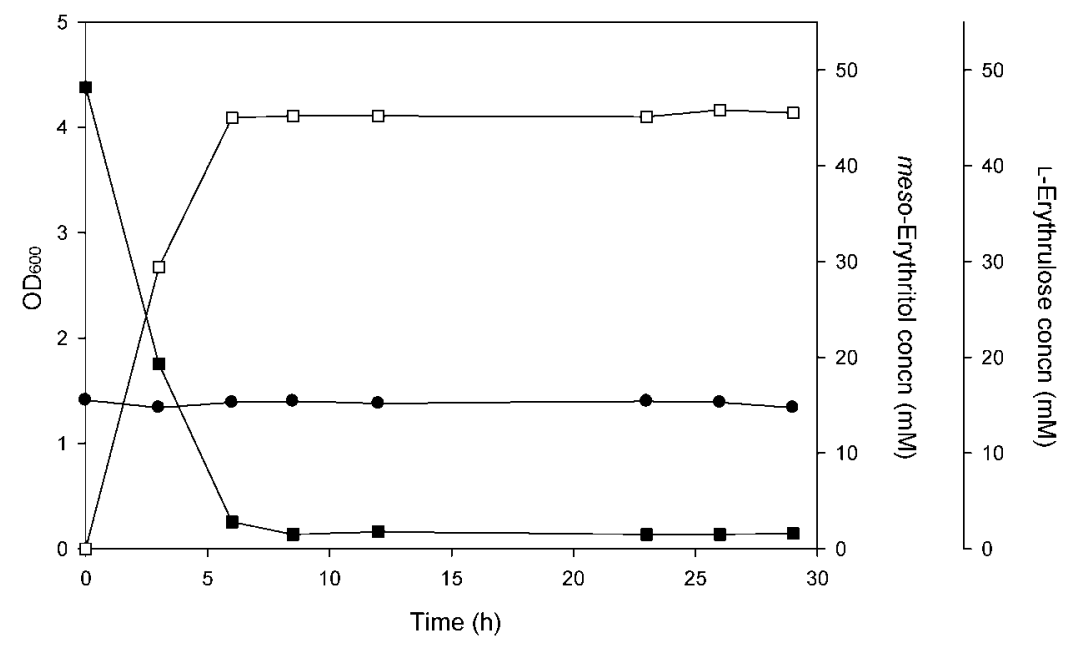

Fig. 2. Conversion of $50 \mathrm{mM}$ meso-erythritol to L-erythrulose by resting cells of $G$. oxydans DSM 7145. Symbols: $\bullet, \mathrm{OD}_{600} ; \mathbf{\square}$, mesoerythritol concentration (mM); $\square$, L-erythrulose concentration (mM). 
(a)

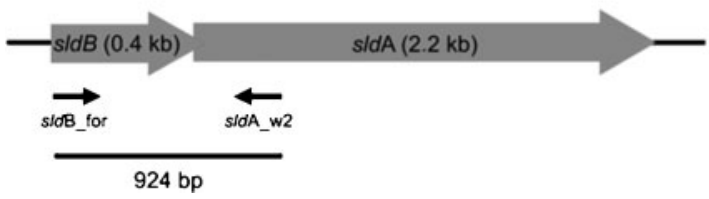

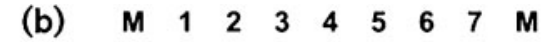

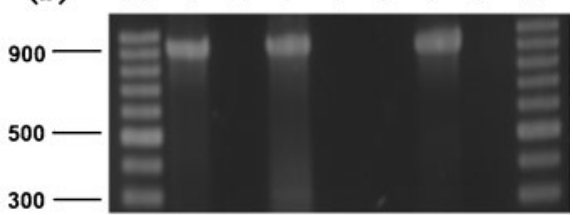

Fig. 3. Genetic organization and operon analysis of the s/dBA genes in G. oxydans DSM 7145. (a) Arrangement of the s/dBA genes (grey arrows) in G. oxydans DSM 7145. (b) Operon analysis of the s/dBA genes. cDNA synthesized from total RNA of cells grown either on D-glucose (lane 1) or on D-glucose/D-mannitol (lane 2) was used as template in PCR experiments with primers s/dB_for and s/dA_w2 (Table 2). Negative controls without prior reverse-transcriptase treatment are shown in lanes 3 and 4, respectively. The product obtained from a PCR with genomic DNA is depicted in lane 6. Lanes 5 and 7 represent nontemplate controls of the PCRs. The predicted fragment size was $924 \mathrm{bp}$.

inactivation of the sldA gene. For inactivation, an internal $1.5 \mathrm{~kb}$ fragment of the sldA gene was replaced by a $1 \mathrm{~kb}$ Gm-resistance cassette. In this mutant, designated $G$. oxydans DSM 7145 sldA:: $\mathrm{Gm}$, more than $67 \%$ of the sldA gene was deleted. The successful disruption of the sldA gene and the absence of the vector in the chromosome were verified by PCR and Southern blot analysis (data not shown).

\section{Growth of G. oxydans DSM 7145 and G. oxydans DSM 7145 s/dA : : Gm on different carbon sources}

Growth of the mutant was monitored on complex medium supplemented with meso-erythritol and other carbon sources known to be utilized by G. oxydans DSM 7145 . Disruption of sldA severely impaired growth of the resulting strain G. oxydans DSM 7145 sldA::Gm on complex medium with glycerol, meso-erythritol and Dmannitol. No growth was observed on meso-erythritol and D-mannitol, while growth on glycerol was slowed down by a factor of three. After $24 \mathrm{~h}$ the mutant reached an optical density on glycerol resembling that of the wild-type strain DSM 7145.

Growth of G. oxydans DSM 7145 sldA:: Gm on D-glucose was slightly impaired and the mutant also reached a final optical density that was lower than that of the wild-type. On a mixture of $25 \mathrm{mM}$ D-glucose $/ 25 \mathrm{mM}$ D-mannitol the growth rate of G. oxydans DSM 7145 sldA:: Gm resembled that of the wild-type grown on D-glucose $\left(0.65 \mathrm{~h}^{-1}\right)$ and also the final optical density was comparable with the value reached by $G$. oxydans DSM 7145 grown on Dglucose $\left(\mathrm{OD}_{600} \sim 0.7\right)$. This seems noteworthy, because on D-glucose/D-mannitol the wild-type grew at a rate $\left(0.46 \mathrm{~h}^{-1}\right)$ and to a final optical density $\left(\mathrm{OD}_{600} \sim 2\right)$ comparable with the values obtained for cultivation on Dmannitol.

These results suggest that the glycerol dehydrogenase indeed oxidizes meso-erythritol in vivo, and in addition seems to have a broader substrate spectrum that also includes at least glycerol and D-mannitol.

\section{Biochemical characterization of G. oxydans DSM 7145 s/dA : : Gm}

To biochemically examine the effect of sldA disruption, membrane fractions of G. oxydans DSM 7145 and $G$. oxydans DSM 7145 sldA:: Gm grown on complex medium with D-glucose to late exponential phase were prepared. These were subsequently used to assay the dye-linked dehydrogenase activities with different substrates. As shown in Fig. 4, sldA disruption did not negatively affect membrane-bound D-glucose oxidation. In G. oxydans DSM 7145 sldA::Gm, D-glucose oxidation was even slightly higher than in the wild-type. Apart from D-glucose, significant D-gluconate oxidation $\left[0.18 \mathrm{U}(\mathrm{mg} \text { protein })^{-1}\right.$, about $42 \%$ of the wild-type level] was retained in the membrane fraction of G. oxydans DSM 7145 sldA:: Gm. On the other hand, oxidation of the tested polyols glycerol, meso-erythritol, D-arabitol, D-mannitol and D-sorbitol was significantly reduced in the membrane fraction of $G$. oxydans DSM 7145 sldA:: Gm as compared with the wildtype membranes. Thus, the glycerol dehydrogenase from $G$. oxydans DSM 7145 not only oxidizes meso-erythritol but has a broad substrate spectrum that includes the sugar acid D-gluconate and the C3-C6 polyols glycerol, D-arabitol, Dmannitol and D-sorbitol.

\section{Glycerol dehydrogenase activities in membrane fractions of cells grown on complex medium with 25 mM D-glucose/25 mM D-mannitol}

To exclude the possibility that other membrane-bound dehydrogenases catalysing the oxidation of meso-erythritol are induced during growth on carbon sources other than D-glucose, G. oxydans DSM 7145 and G. oxydans DSM 7145 sldA:: Gm were cultivated on complex medium with $25 \mathrm{mM}$ D-glucose/D-mannitol to late exponential phase. Based on the data depicted in Fig. 4, SldA seems to be the main polyol dehydrogenase in G. oxydans DSM 7145. Oxidation of glycerol, meso-erythritol, D-arabitol, Dmannitol, D-sorbitol and D-gluconate was also clearly reduced in the membrane fraction of G. oxydans DSM 7145 sldA:: Gm grown in a mixture of D-glucose/D-mannitol. 


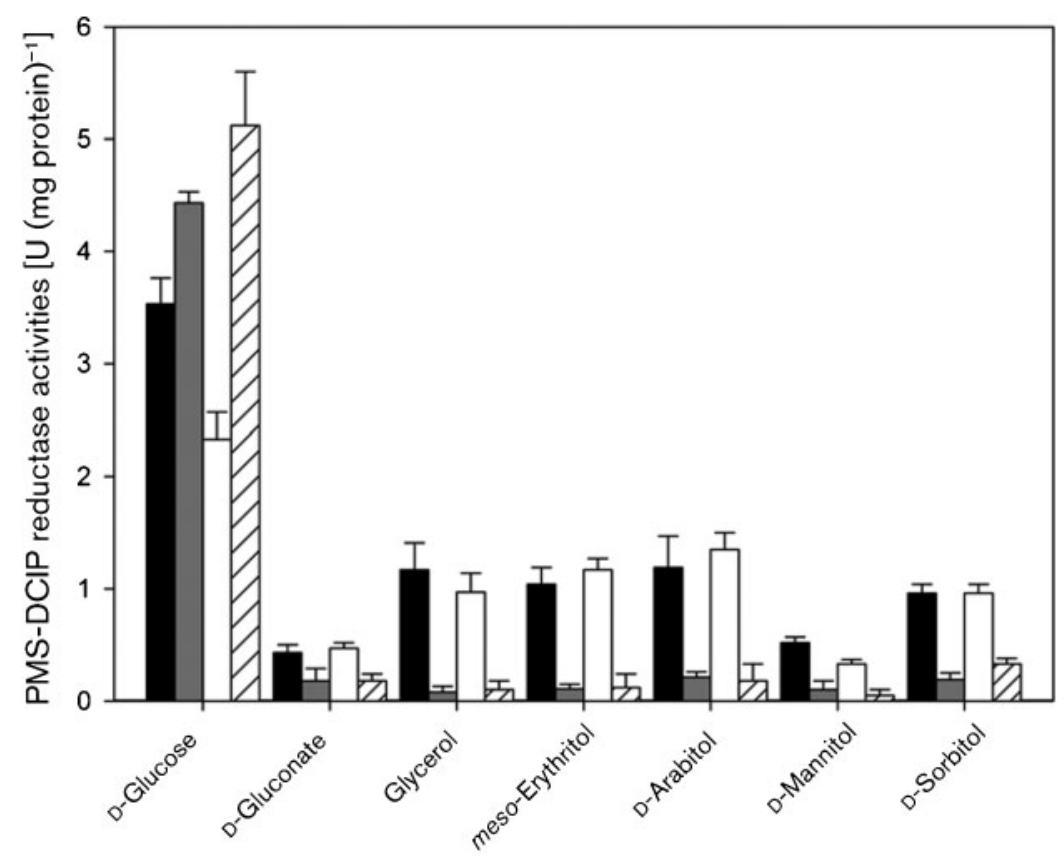

Fig. 4. Membrane-bound dehydrogenase activities in G. oxydans DSM 7145. Membrane fractions were prepared from cells grown on complex medium supplemented with $50 \mathrm{mM}$ D-glucose or $25 \mathrm{mM}$ D-glucose/ $25 \mathrm{mM}$ D-mannitol to late exponential phase. Black bars, membrane-bound enzyme activities in G. oxydans DSM 7145 grown on $50 \mathrm{mM}$ D-glucose; grey bars, membranebound activities in G. oxydans DSM 7145 s/dA:: Gm grown on $50 \mathrm{mM}$ D-glucose; white bars, membrane-bound activities in G. oxydans DSM 7145 grown on $25 \mathrm{mM}$ D-glucose/ 25 mM D-mannitol; hatched bars, membranebound activities in G. oxydans DSM 7145 sldA::Gm grown on $25 \mathrm{mM}$ D-glucose/ $25 \mathrm{mM}$ D-mannitol. Assays were performed as described in Methods. The data shown are mean values from three replicate experiments.

Moreover, Fig. 4 shows that the glycerol dehydrogenase seems to be expressed constitutively, irrespective of the utilized carbon source, because similar PMS-DCIP reductase activities were detected in membrane fractions of cultures grown on D-glucose and D-glucose/D-mannitol. In contrast, differences in membrane-bound D-glucose oxidation were observed. In wild-type membrane fractions, glucose dehydrogenase decreased with the D-glucose concentration in the medium, while membrane fractions of G. oxydans DSM 7145 sldA:: Gm revealed elevated Dglucose oxidation rates.

\section{Complementation of G. oxydans DSM 7145 s/dA : : Gm}

To complement G. oxydans DSM 7145 sldA::Gm, a plasmid, pJV8, containing the putative $s l d B$ promoter region fused to the sldA gene was constructed. This construct efficiently restored growth of G. oxydans DSM 7145 sldA:: Gm on complex medium with D-mannitol, meso-erythritol and glycerol (data not shown). Differences were observed in the final optical densities. While $G$. oxydans DSM 7145 sldA:: Gm(pJV8) grown on glycerol and meso-erythritol reached values comparable with those of the vector control, only half of the final optical density of the control was reached when G. oxydans DSM 7145 sldA::Gm(pJV8) was cultivated on D-mannitol. Membrane fractions of the complemented mutant again oxidized glycerol, meso-erythritol, D-arabitol, D-mannitol, D-sorbitol and D-gluconate. The observed ratio of the dehydrogenase activities of the vector control and the complemented mutant was 0.7 for most substrates, except for D-gluconate, where the ratio was 0.89 .

\section{DISCUSSION}

In this study it was shown that G. oxydans DSM 7145 not only utilizes meso-erythritol but also L-erythrulose as growth substrate, and that both substrates are metabolized by different pathways. Oxidation of meso-erythritol is membrane-associated, mediated by the glycerol dehydrogenase (discussed below) and results in nearly quantitative accumulation of L-erythrulose in culture supernatants. Depletion of extracellular meso-erythritol leads to a global metabolic change from membrane-bound meso-erythritol oxidation to L-erythrulose assimilation accompanied by acetate accumulation. In the cytoplasm, L-erythrulose is most likely reduced to meso-erythritol by an $\mathrm{NAD}(\mathrm{P})^{+}$dependent dehydrogenase, as similarly discussed with ribitol dehydrogenase from G. suboxydans IFO 12528 (Adachi et al., 2001), and then channelled into the pentose-phosphate pathway. Acetate is probably produced from the glyceraldehyde 3-phosphate generated in the pentose-phosphate pathway via pyruvate and acetaldehyde, as the genome sequence of $G$. oxydans ATCC $621 \mathrm{H}$ reveals a missing acetate kinase pathway but the presence of a pyruvate decarboxylase and an $\mathrm{NADP}^{+}$-dependent acetaldehyde dehydrogenase (Prust et al., 2005; Schweiger et al., 2007). Gluconobacter frateurii CHM 43 has also been shown to grow on meso-erythritol and L-erythrulose (Moonmangmee et al., 2002), but L-erythrulose consumption linked to extracellular accumulation of acetic acid has not been previously reported.

Excretion of acetic acid by G. oxydans DSM 7145 is most likely only a by-product of intracellular L-erythrulose metabolism, because $30 \mathrm{mM}$ L-erythrulose was consumed but only $10 \mathrm{mM}$ acetic acid was detectable in the culture 
supernatants (Fig. 1b). As has been shown for E. coli aerobic acetate production, this is a manifestation of an imbalance between glucose uptake and the demands for both biosynthesis and energy production (El-Mansi \& Holms, 1989). Thus, it can be assumed that L-erythrulose cannot be channelled into the cytoplasmic pathways fast enough and therefore part of the internalized L-erythrulose is converted to acetic acid.

A further physiological explanation of the observed biphasic metabolism of meso-erythritol could be that $G$. oxydans DSM 7145 first quickly oxidizes meso-erythritol to an unfavourable product, L-erythrulose, thereby preventing growth and utilization of erythritol by other bacteria. Afterwards, L-erythrulose is slowly utilized, similar to the hypothesis of L-sorbose utilization by $\mathrm{G}$. frateurii CHM 43 (Soemphol et al., 2007).

As meso-erythritol oxidation was solely localized in membrane fractions of G. oxydans DSM 7145, it seemed reasonable that an enzyme similar to the membrane-bound glycerol dehydrogenase of G. suboxydans (Matsushita et al., 2003) catalyses meso-erythritol oxidation in G. oxydans DSM 7145. Sequencing of the identified homologues from strain DSM 7145 revealed not only that they are highly similar to the sldBA genes of G. oxydans ATCC 621H (gox 0854-0855) (Prust et al., 2005) and G. suboxydans IFO 3255 (Miyazaki et al., 2002) but also that the genes seem to be organized in an operon (Fig. 3). Only few promoters of acetic acid bacteria have been characterized to date, so we decided to elucidate the mode of transcription of the sldBA genes. Our experiments showed that these two genes are indeed transcribed polycistronically from a promoter upstream of sldB. Co-transcription may also take place in G. suboxydans IFO 3255, as was speculated by Miyazaki et al. (2002), and may also occur in other Gluconobacter strains with a similar genetic organization of the sldBA genes.

To test the hypothesis that meso-erythritol is a substrate of the membrane-bound glycerol dehydrogenase, the sldA gene was inactivated by insertion of a $\mathrm{Gm}$-resistance gene. Growth experiments with meso-erythritol and other substrates known to be utilized by G. oxydans DSM 7145 indicated that meso-erythritol and other C3-C6 polyols but not D-glucose are substrates of the glycerol dehydrogenase. The broad substrate spectrum of the enzyme could be further confirmed by biochemical characterization of the mutant. While D-glucose oxidation was retained in membrane fractions of G. oxydans DSM 7145 sldA:: Gm, oxidation of the C3-C6 polyols glycerol, meso-erythritol, D-arabitol, D-mannitol and D-sorbitol, and also of the sugar acid D-gluconate was significantly reduced. The substrate spectrum determined closely matches that of the glycerol dehydrogenases of G. suboxydans IFO 3255 and 3257, which have also been shown to catalyse the oxidation of some polyols and D-gluconate (Matsushita et al., 2003; Shinjoh et al., 2002).

The glycerol dehydrogenase seems to be the main enzyme involved in the oxidation of the substrates mentioned above, as the corresponding oxidation activities were also significantly reduced in membrane fractions of G. oxydans DSM 7145 sldA:: Gm grown on a different carbon source. The residual oxidation of polyols can be attributed to other dehydrogenases present in the membrane fraction of $G$. oxydans DSM 7145, which most likely oxidize the SldA substrates at a low rate.

Interestingly, expression of the polyol dehydrogenase seems not to be regulated, as PMS-DCIP reductase activities measured in membrane fractions of cells grown on Dglucose (non-SldA substrate) did not increase by addition of the substrate D-mannitol to the growth medium (Fig. 4). Similarly, De Ley \& Dochy (1960) and DeLey \& Stouthamer (1959) concluded from the examination of D-glucose metabolism in Acetobacter spp. that expression of the enzymes involved is not regulated. Genome-wide transcription analysis of G. oxydans ATCC $621 \mathrm{H}$ further confirmed that most membrane-bound dehydrogenases are expressed constitutively, irrespective of the utilized carbon source (our unpublished results). Therefore, we conclude that for industrial production of L-erythrulose, G. oxydans DSM 7145 can also be cultured on glucose-containing medium to obtain biomass, which then can be used in resting cell preparations to oxidize meso-erythritol to Lerythrulose (Fig. 2).

In contrast to the glycerol dehydrogenase, differences were observed in membrane-bound D-glucose oxidation. In the wild-type background, membrane-bound D-glucose oxidation activity was lower in cultures grown on D-glucose/Dmannitol than in cultures grown on D-glucose. Additionally, elevated dye-linked glucose dehydrogenase activities were detectable in G. oxydans DSM 7145 sldA:: Gm (Fig. 4). At present, the reasons for these differences are not clearly understood, as no differences in expression of the sldA gene and the $m g d h$ gene, encoding the membrane-bound D-glucose dehydrogenase, were detectable (our unpublished results). Gupta et al. (1997) attributed elevated gluconate- and 2-keto-D-gluconateoxidizing activities after transposon-induced inactivation of the membrane-bound glucose dehydrogenase in $G$. oxydans ATCC 9937 to a decontrol or activation of the genes encoding the respective enzymes. Such polar effects on the expression of genes distal to the insertion site have been described before (Kleckner et al., 1977) but can be ruled out in this case because neither in G. oxydans ATCC $621 \mathrm{H}$ nor in G. oxydans DSM 7145 are the sldBA and the $m g d h$ genes organized in operons.

The ongoing work with G. oxydans DSM 7145 showed that this strain seems to be genetically similar to G. oxydans ATCC $621 \mathrm{H}$. Nonetheless, physiological differences between the two strains were noted. With G. oxydans ATCC $621 \mathrm{H}$, only a minor decrease in extracellular Lerythrulose concentration was observed after the supplied meso-erythritol was depleted. Moreover, in contrast to $G$. oxydans ATCC $621 \mathrm{H}$, the sacB selection strategy (Gay et al., 1985) could be applied in G. oxydans DSM 7145 to identify 
double-crossover mutants. Based on these observations, sequencing of other G. oxydans genomes seems interesting in order to elucidate whether physiological differences can be traced back to genomic differences or whether other regulatory mechanisms are involved.

\section{ACKNOWLEDGEMENTS}

We are especially grateful to Professor Ivo Feussner, Department of Plant Biochemistry, University of Göttingen, for performing GC-MS analysis of culture supernatants. The contribution of Julia Suurbach, who participated as intern on the initial steps of the project, is also cordially acknowledged. The project was carried out within the framework 'BiotechGenoMik' supported by the German Federal Ministry of Education and Research (BMBF).

\section{REFERENCES}

Adachi, O., Fujii, Y., Ano, Y., Moonmangmee, D., Toyama, H., Shinagawa, E., Theeragool, G., Lotong, N. \& Matsushita, K. (2001). Membrane-bound sugar alcohol dehydrogenase in acetic acid bacteria catalyzes L-ribulose formation and NAD-dependent ribitol dehydrogenase is independent of the oxidative fermentation. Biosci Biotechnol Biochem 65, 115-125.

Adachi, O., Moonmangmee, D., Toyama, H., Yamada, M., Shinagawa, E. \& Matushita, K. (2003). New developments in oxidative fermentation. Appl Microbiol Biotechnol 60, 643-653.

Altschul, S. F., Madden, T. L., Schaffer, A. A., Zhang, J., Zhang, Z., Miller, W. \& Lipman, D. J. (1997). Gapped BLAST and PSI-BLAST: a new generation of protein database search programs. Nucleic Acids Res 25, 3389-3402.

Bendtsen, J. D., Nielsen, H., von Heijne, G. \& Brunak, S. (2004). Improved prediction of signal peptides: SignalP 3.0. J Mol Biol 340, 783-795.

Bergmeyer, H. U. (1974). Methoden der Enzymatischen Analyse, 3rd edn. Weinheim: Verlag Chemie.

Bonfield, J. K., Smith, K. \& Staden, R. (1995). A new DNA sequence assembly program. Nucleic Acids Res 23, 4992-4999.

Bullock, W. O., Fernandez, J. M. \& Short, J. M. (1987). XL-1 Blue: a high efficiency plasmid DNA transforming recA E. coli strain with beta-galactosidase selection. Biotechniques 5, 376-379.

Cozier, G. E. \& Anthony, C. (1995). Structure of the quinoprotein glucose dehydrogenase of Escherichia coli modelled on that of methanol dehydrogenase from Methylobacterium extorquens. Biochem J 312, 679-685.

Davidson, V. L. (2004). Electron transfer in quinoproteins. Arch Biochem Biophys 428, 32-40.

De Ley, J. \& Dochy, R. (1960). On the localization of oxidase systems in Acetobacter cells. Biochim Biophys Acta 40, 277-289.

De Ley, J. \& Stouthamer, A. H. (1959). The mechanism and localization of hexanoate metabolism in Acetobacter suboxydans and Acetobacter melanogenum. Biochim Biophys Acta 34, 171-183.

De Muynck, C., Pereira, C. S. S., Naessens, M., Parmentier, S., Soetaert, W. \& Vandamme, E. J. (2007). The genus Gluconobacter oxydans: comprehensive overview of biochemistry and biotechnological applications. Crit Rev Biotechnol 27, 147-171.

El-Mansi, E. M. T. \& Holms, W. H. (1989). Control of carbon flux to acetate excretion during growth of Escherichia coli in batch and continuous cultures. J Gen Microbiol 135, 2875-2883.
Gay, P., Lecoq, D., Steinmetz, M., Berkelman, T. \& Kado, C. I. (1985). Positive selection procedure for entrapment of insertion sequence elements in Gram-negative bacteria. J Bacteriol 164, 918-921.

Ghosh, M., Anthony, C., Harlos, K., Goodwin, M. G. \& Blake, C. (1995). The refined structure of the quinoprotein methanol dehydrogenase from Methylobacterium extorquens at $1.94 \AA$. Structure 3, 177-187.

Gupta, A., Verma, V. \& Qazi, G. N. (1997). Transposon induced mutation in Gluconobacter oxydans with special reference to its directglucose oxidation metabolism. FEMS Microbiol Lett 147, 181-188.

Kleckner, N., Roth, J. \& Botstein, D. (1977). Genetic engineering in vivo using translocatable drug resistance elements: new methods in bacterial genetics. J Mol Biol 116, 125-159.

Kondo, K. \& Horinouchi, S. (1997). Characterization of the genes encoding the three-component membrane-bound alcohol dehydrogenase from Gluconobacter suboxydans and their expression in Acetobacter pasteurianus. Appl Environ Microbiol 63, 1131-1138.

Kovach, M. E., Elzer, P. H., Hill, D. S., Robertson, G. T., Farris, M. A., Roop, R. M. I. \& Peterson, K. M. (1995). Four new derivatives of the broad-host-range cloning vector pBBR1MCS, carrying different antibiotic-resistance cassettes. Gene 166, 175-176.

Kulhanek, M. (1989). Microbial dehydrogenations of monosaccharides. Adv Appl Microbiol 34, 141-181.

Larkin, M. A., Blackshields, G., Brown, N. P., Chenna, R., McGettigan, P. A., McWilliam, H., Valentin, F., Wallace, I. M., Wilm, A. \& other authors (2007). CLUSTAL $\mathrm{W}$ and CLUSTAL_X version 2. Bioinformatics 23, 2947-2948.

Mason, L. M. \& Claus, G. W. (1989). Phenotypic characteristics correlated with deoxyribonucleic acid sequence similarities for three species of Gluconobacter: G. oxydans (Henneberg 1897) De Ley 1961, G. frateurii sp. nov., and G. asaii sp. nov. Int J Syst Bacteriol 39, 174184.

Matsushita, K., Shinagawa, E., Adachi, O. \& Ameyama, M. (1987). Purification and characterization of cytochrome $o$-type oxidase from Gluconobacter suboxydans. Biochim Biophys Acta 394, 305-312.

Matsushita, K., Toyama, H. \& Adachi, O. (1994). Respiratory chains and bioenergetics of acetic acid bacteria. Adv Microb Physiol 36, 247301.

Matsushita, K., Fujii, Y., Ano, Y., Toyama, H., Shinjoh, M., Tomiyama, N., Miyazaki, N., Sugisawa, T., Hoshino, T. \& other authors (2003). 5Keto-D-gluconate production is catalyzed by a quinoprotein glycerol dehydrogenase, major polyol dehydrogenase, in Gluconobacter species. Appl Environ Microbiol 69, 1959-1966.

Miyazaki, T., Tomiyama, N., Shinjoh, M. \& Hoshino, T. (2002). Molecular cloning and functional expression of D-sorbitol dehydrogenase from Gluconobacter suboxydans IFO3255, which requires pyrroloquinoline quinone and hydrophobic protein SldB for activity development in E. coli. Biosci Biotechnol Biochem 66, 262-270.

Moonmangmee, D., Adachi, O., Shinagawa, E., Toyama, H., Theeragool, G., Lotong, N. \& Matsushita, K. (2002). L-Erythrulose production by oxidative fermentation is catalyzed by PQQ-containing membrane-bound dehydrogenase. Biosci Biotechnol Biochem 66, 307318.

Pestov, N. B. \& Rydström, J. (2007). Purification of recombinant membrane proteins tagged with calmodulin-binding domains by affinity chromatography on calmodulin-agarose: example of nicotinamide nucleotide transhydrogenase. Nat Protoc 2, 198-202.

Prust, C., Hoffmeister, M., Liesegang, H., Wiezer, A., Fricke, W. F., Ehrenreich, A., Gottschalk, G. \& Deppenmeier, U. (2005). Complete genome sequence of the acetic acid bacterium Gluconobacter oxydans. Nat Biotechnol 23, 195-200. 
Sambrook, J., Fritsch, E. F. \& Maniatis, T. (1989). Molecular Cloning, a Laboratory Manual, 2nd edn. Cold Spring Harbor, NY: Cold Spring Harbor Laboratory.

Schäfer, A., Tauch, A., Jäger, W., Kalinowski, J., Thierbach, G. \& Pühler, A. (1994). Small mobilizable multi-purpose cloning vectors derived from the Escherichia coli plasmids pK18 and pK19: selection of defined deletions in the chromosome of Corynebacterium glutamicum. Gene 145, 69-73.

Schedel, M. (2000). Regioselective oxidation of aminosorbitol with Gluconobacter oxydans, a key reaction in the industrial synthesis of 1deoxynojirimycin. In Biotechnology, pp. 296-308, Edited by D. Kelly. Weinheim: Wiley-VCH.

Schweiger, P., Volland, S. \& Deppenmeier, U. (2007). Overproduction and characterization of two distinct aldehyde oxidizing enzymes from Gluconobacter oxydans 621H. J Mol Microbiol Biotechnol 13, 147-155.

Shinjoh, M., Tomiyama, N., Miyazaki, T. \& Hoshino, T. (2002). Main polyol dehydrogenase of Gluconobacter suboxydans IFO 3255, membrane-bound D-sorbitol dehydrogenase, that needs product of upstream gene, sldB, for activity. Biosci Biotechnol Biochem 66, 23142322.

Simon, R., Priefer, U. \& Pühler, A. (1983). A broad host range mobilization system for in vivo genetic engineering: transposon mutagenesis in Gram-negative bacteria. Biotechnology 1, 784791.

Soemphol, W., Toyama, H., Moonmangmee, D., Adachi, O. \& Matsushita, K. (2007). L-Sorbose reductase and its transcriptional regulator involved in L-sorbose utilization of Gluconobacter frateurii. J Bacteriol 189, 4800-4808.

Tschamber, T., Craig, C. J., Muller, M. \& Streith, J. (1996). Stereoselective synthesis of D,L-erythrose-, and of D,L-1,4-dideoxy-4aminoerythrose derivatives bearing B lactam at C-4. Tetrahedron 52, 6201-6214.

Wach, A. (1996). PCR-synthesis of marker cassettes with long flanking homology regions for gene disruptions in S. cerevisiae. Yeast 12, 259265.

Edited by: H. L. Drake 